\title{
TRTaKadeMi
}

ISSN 2149-9446 | Cilt 06 | Sayı 13 | Eylül 2021 | Yapay Zekâ

\section{Yapay Zekâ ve Kişiselleştirilmiş Seyir Kültürü: Netflix Örneği Üzerinden Sanat Eserinin Hiper Kişiselleştirilmesi}

\author{
Ferhat ZENGIN*
}

\begin{abstract}
Öz
Yapay zekâ teknolojilerinin tüketici davranışlarını etkilemeye ve yeni tüketim alışkanlıkları oluşturmaya başlaması iletişim alanında ortaya yeni kavramların çıkmasına neden olmaktadır. Hiper kişiselleştirme de bu yeni kavramlardan bir tanesidir. Hiper kişiselleştirme, tüketici alışkanlıklarını ve eğilimini "bire bir" temas noktalarından etkilemeye yönelik olarak yapay zekâ tabanlı gelişen bir kavramdır. Bu çalışmanın amacı, yeni bir olgu olarak karşımıza çıkan hiper kişiselleştirmenin, çevrim içi video akış siteleri üzerinden araştrıımasıdır. Bu bağlamda hiper kişiselleştirilmiş içeriklerin çevrim içi izleme pratiklerini etkilemeye ve yönlendirmeye dönük girişimleri Netflix örneği üzerinden betimsel analiz yöntemiyle incelenmiştir. Çalışmada literatür taraması yapılmış ve çeşitli teorik tartışmalara yer verilmiştir. Bu araştırmada hiper kişiselleştirilmiş içeriklerin tüketici davranışlarını ve izleme alışkanlıklarını yönlendirmede başat bir araç olarak kullanıldığını ortaya koymuş, sinema sanatında seyir kültürünün bireyselleşmeye doğru yöneliş gösterdiğini tespit etmiştir.
\end{abstract}

Anahtar Kelimeler: Hiper Kişiselleştirme, Kişiselleştirme, Netflix, Yapay Zekâ, Sinema Seyir Kültürü, Dijital Sinema

*Dr. Öğr. Üyesi, İstanbul Gelişim Üniversitesi, Uygulamalı Bilimler Fakültesi, Televizyon Haberciliği ve Programcılığı Bölümü, ferhatbzengin@gmail.com

Zengin, F. (2021). Yapay Zekâ ve Kişiselleştirilmiş Seyir Kültürü: Netflix Örneği Üzerinden Sanat Eserinin Hiper Kişiselleştirilmesi . TRT Akademi , 6 (13) , 700-727 . DOI: 10.37679/trta.959576

\section{Araştırma Makalesi}




\title{
TRTakadeMi
}

ISSN 2149-9446 | Volume 06 | Issue 13 | September 2021 | Artificial Intelligence

\section{Artificial Intelligence and Personalized Viewing Culture: Hyper-Personalization of Art Works on Netflix}

\author{
Ferhat ZENGIN
}

\begin{abstract}
Artificial intelligence technologies started to influence consumer behaviours and create new consumption habits. Therefore, new concepts have emerged in the field of communication. Hyper-personalisation is one of these new concepts. Hyper-personalisation is a new concept developed based on artificial intelligence towards influencing consumer habits and tendencies at "one-to-one" contact points. The purpose of this study is to investigate hyperpersonalisation as a new phenomenon of online video streaming websites. The attempts of hyper-personalisation content on influencing and direction online watching practices are investigated over Netflix example. A literature review is applied in this study and various theoretical discussions are included. In this study reveals that Hyper-personalisation content is a determinative tool to direct consumer behaviours and watching habits and predicted individualisation in watching the culture of cinema art.
\end{abstract}

Keywords: Hyper Personalization, Personalization, Netflix, Artificial Intelligence, Cinema Viewing Culture, Digital Cinema 


\section{Giriş}

Sinemanın erken döneminde ilk toplu gösterimler yapılmadan önce hareketli görüntülerin bireysel olarak alımlandığı, kişiye özel film gösterimlerinin yapıldığı bilinmektedir. Bu gösterimler, Amerikalı Mucit Thomas Alva Edison'un 1891'de yardımcısı William K.L. Dickson ile birlikte icat ettikleri kinetoskop (kinetoscope) aygıtiyla gerçekleştirilmişti. Sadece tek bir kişi tarafindan filmlerin izlenebildiği bir gösterim cihazı olan kinetoskop, Ali Özuyar’a göre, "O güne dek gerçekleştirilen en gelişmiş sinematografik izleme teknolojisidir." ve piyasaya sürülmesinden kısa bir süre sonra dünya çapında büyük bir başarı elde etmiştir (2017, s. 16). Fakat film seyretmenin biçimini ve sinemanın doğuşunu belirleyen (Abisel, 2003, s. 29) teknoloji, Lumière Kardeşler'in 1895'te icat ettiği sinematograf (cinématographe) kamerasıdır. Hem kamera hem de bir gösterim cihazı olan sinematografin, sinemanın doğuşuyla nitelendirilmesinin nedeni ise bu teknolojiyle birlikte ortaya çıkan toplu seyir kültürüdür. Buna göre Edison'un kinetoskop salonlarında tek kişi olarak izlenen filmlerin aksine Lumière'ler, sinematograf cihazıyla beyaz perdeye yansıttıkları filmlerini toplu gösterim yaparak gerçekleştirmişlerdir. Günümüze kadar devam eden söz konusu bu seyir biçiminden dolayı sinema kavramı çoğunlukla film, sinema salonu ve seyirci ilişkisinden hareket edilerek tanımlanmaya çalışılmıştr. Başka bir deyişle bu algının temel nedeni sinemanın ilk deneyimler açısından salonlarda izlenmesi veya kendine özgü yerlerde bir ritüelmiş gibi yaşanmasının etkisidir (Kırel, 2010, s. 17).

New York Üniversitesi profesörlerinden lan C. Jarvie'nin vurguladığı gibi, “Sinema tam anlamıyla bir kitle sanatıdır yalnız seyirci kitlesine hitap ettiği için değil, kişinin sürekli devam eden gösterinin karanlığında kaybolmuş olması yüzündendir. Etrafinda kimin oturduğunun farkında değildir, film boyunca çevresiyle sosyal bir alışverişi olmaz ve kimse görmeden çıkıştan gizlice kaçabilir. Yine de sinemaya gitmenin sosyal bir unsuru vardır. Tam olarak yalnız yapılan bir faaliyet de değildir. Aileyle, okulla, arkadaş gruplarıyla ve sevgiliyle gidilebilir. Sinema bütün bu grupların bir arada katılmaktan mutluluk duydukları bir faaliyettir" (Jarvie, 1993, s. 23). Jarvie'den hareketle sosyal ve kültürel bir olgu olarak karşımıza çıkan sinema uzun yıllar sinemaya gitmekten filmlerin seyredildiği anı ve sonrasını kapsayan ritüeller şeklinde deneyimlenmiştir. Fakat pelikül filmden dijital filme geçiş sinema medyumunda radikal değişikliklere neden olmuştur. Yeni medya kuramcısı Lev Manovich, sinema teknolojilerinde yaşanan dijitalleşmeyi sinemanın yeniden icadı olarak görür (2014, s. 172). Ona göre sinemadaki dijitalleşme, sinemanın ilk yıllarına geri dönüştür (1995). Dijital sinema üzerine çalışan ilk akademisyenlerden olan John Belton (2002) ise dijital sinemayı, sadece "ev-eğlence" (home 
entertainment) pazarının gelişmesini sağlayacak sahte bir devrim olarak açıklar. Manovich ve Belton'un vurguladığı "sinemanın ilk yıllarına geri dönüş" ve "bireyselleşmeye dönük ev eğlence pazarının gelişimi” günümüzde yaşanan film seyir biçimindeki değişimi anlama adına değerlidir.

Sinemanın pelikül döneminde evde film izleme deneyimi olan "home cinema" (ev sineması) kavramının varlığı bilinmekle birlikte, bu deneyimin sinemanın toplu izleme kültürüne çok fazla etkide bulunmadığı bir gerçektir. Fakat bu gerçek dijitalleşmeyle birlikte değişmeye başlamış; video kasetler, diskler (DVD, Blu-ray gibi), yeni film anlatıları (interaktif film gibi), internet tabanlı online film izleme siteleri gibi gelişmelerle bireysel seyir alanına yönelik ev sineması yükselişe geçmiştir. James Monaco'ya göre sinemadaki bu gelişim, kinetoscope modeli tarzının yeniden hayat bulmasıdır (2002, s. 224). Video akış hizmeti sağlayıcılarının buradaki etkisi ise oldukça büyüktür. Özellikle kovid-19 pandemisinin etkisiyle birlikte evlerine sığınan sinema seyircisi, sinema salonlarının bir alternatifi olarak Netflix, Amazon Prime Video, Apple TV+, Disney+ gibi video akış platformlarına yönelmiştir. Büyük bir dalga şeklindeki bu yöneliş, kısa sürede film endüstrisinde büyük bir rekabet ortamının da doğmasına neden olmuştur. Bu bağlamda dijital platformlar, büyük rekabet ortamında yeni aboneler kazanmak için bir yandan yeni içeriklerle kataloglarını zenginleştirmeye çalışırken bir yandan da mevcut aboneleri korumaya yönelik öneri motorları geliştirmeye başlamışlardır. Bu durum da yapay zekâ ve makine öğrenimi teknolojilerinin bu alanlarda kullanılmasının önünü açmıştır.

Günümüzde şirketler, tüketicilerine ya da müşterilerine en iyi hizmeti sunmak ya da gelecekteki potansiyel katılımcılarını artırmak amacıyla hizmet sundukları çevrim içi platformlarında öneri motorları kullanmakta ve bunun için de kişisel verilere daha fazla ihtiyaç duymaktadır. Şirketlerin bu ihtiyacı karşılaması da müşterileriyle etkileşimlerini artırmasına bağlıdır. Çünkü etkileşim, müşteri verilerini toplamada şirketlere büyük kolaylıklar sağlar. Yönetim danışmanlığı ve teknoloji hizmetleri sunan Accenture'ın 2016 tarihli araştırmasına göre, tüketicilerin çoğu markaların kendileri için sunduğu kişiselleştirilmiş önerilere olumlu yaklaşmaktadır. Buna göre tüketiciler, kendilerini tanıyan (\%56'sı), alakalı öneriler sunan (\%58'i), satın alma geçmişiyle kendisini hatırlayan (\%65’i) markalarla alışveriş yapmaya daha fazla istek göstermektedir. Tüketicilerin bu üç hizmetten herhangi birini sunan perakendecilerle alışveriş yapma olasılığı ise \%75'tir (Accenture, 2016). Aynı araştırmanın 2018 verilerine göre bu oran yüzde 91'e çıkmıştır (Accenture, 2018, s. 3). Dolayısıyla dijital dönemin müşterileri, kendilerinin markalarca bilinmesini ve farkına varılmasını istemektedir. 
"Yeni teknolojiler şirketlere, belirli bireyleri tanımlamak ve karakterize etmek için daha büyük ölçekte veri toplanmasına ve onları analiz etmesine imkân sağlamaktadır. Dolayısıyla şirketler artık belirli bir müşteriyle doğrudan temasa geçebilir ve ona sadece kişiye özel bir ürün/hizmet değil, aynı zamanda hiper kişiselleştirilmiş bir deneyim de sunabilmektedir" (Capgemini \& ESSEC, 2017, s. 3). Burada sözü geçen hiper kişiselleştirme, müşteri odaklı hâle gelen dijital pazarlama yaklaşımını karşılayan yeni bir kavramdır. Bu pazarlama yaklaşımı doğru zamanda doğru kişiye doğru içeriği sunmayı amaçlar (Subramanyan, 2014).

Accenture'ın araştırmasına göre video akış platformları kişiselleştirme konusunda önde gelen endüstriler arasında yer alır. Çünkü buradaki aboneler kişisel verilerin kullanımı söz konusu olduğunda daha iyi bir kişiselleştirme için kendi verilerinin kullanılmasından rahatsızlık duymamaktadır. Araştırmaya göre her üç kişiden ikisi (\%66) video akış sitelerinin beğenebilecekleri ürün ve içerikler önermesi şartıyla kendi verilerini kullanmasından memnundur (Accenture, 2016). Bu bağlamda dijital dönemin tüketicileri kişiselleştirilmiş tüketici eğilimlerine daha fazla ilgi göstermektedir. Bu bilgiden hareketle video akış platformları da abonelerine daha iyi hizmet sağlama ve onlarla yakınlaşma adına yapay zekâ tabanlı gelişen hiper kişiselleştirme yaklaşımını kullanmaya başlamıştır.

Bu çalışmanın temel amacı da yeni bir olgu olarak karşımıza çıkan hiper kişiselleştirmenin video akış siteleri üzerinden araştırılmasıdır. Çalışmada hiper kişiselleştirilmiş içeriklerin, çevrim içi izleme pratiklerini etkilemeye ve yönlendirmeye dönük girişimleri incelenecektir. Buradan hareketle çalışma, abone sayısı bakımından pazar lideri konumunda olan Netflix örneklemi üzerinden ele alınacaktır. Çalışma, hiper kişiselleştirilmiş önerilerin kişisel ve deneyimsel veriler üzerinden Netflix'te nasıl oluşturulduğunu açıklayacak ve hiper kişiselleştirmenin çevrim içi video akış siteleri için potansiyel önemini ortaya koyacaktır.

Hiper kişiselleştirilmiş öneri motorları ve bu teknolojilerin etkilerini ölçme ve değerlendirme çalışmaları oldukça sınırlıdır. Dolayısıyla günümüzün bu popüler teknolojileri hakkında bilimsel çalışmalara ihtiyaç duyulmaktadır. Bu çalışma da söz konusu ihtiyaca dayalı olarak ortaya çıkmıştır. Araştırmada literatür taraması ve kuramsal tartş̧malara yer verilerek hiper kişiselleştirme çerçevesinden Netflix'in kişiselleştirme yaklaşımı betimsel analiz yöntemiyle incelenecektir. Çalışmada ihtiyaç duyulan bilgiler ise mikro blog platformu Medium'daki "The Netflix Tech Blog" adlı blog sayfasında yer alan yazılardan edinilecektir. Netflix'in kişiselleştirme algoritmasını inşa eden mühendisler, The Netflix Tech Blog sayfasında Netflix sistemleri hakkında teknik bilgiler ve bakış açıları sunmakta ve bununla birlikte şirket kültürü, ürün geliştirmeleri ve kullanılan yazılımlara ilişkin bir dizi bilgiler 
vermektedir. Herbert Lui'nin verilerine göre "31 Aralık 2020 tarihi itibariyle, Netflix mühendislerinden 526'sı TechBlog'da 407 blog yazısı yayımlamıştır (Lui, 2021). Çalışma, bu yazılardan sadece kişiselleştirme temalı yazılarla sınırlandırılacak; diğer konular araştırmanın dışında bırakılacaktır. Çalışmanın önemi Netflix öneri sisteminin amacını, bakış açısını, kullanımını ve şirketin pazarlama stratejisini nasıl dönüştürdüğünü ortaya koyacak olmasıdır.

\section{Hiper Kişiselleştirme Kavramına Bakış}

"Çoğu zaman insanlar siz onlara gösterene kadar ne istediklerini bilmezler" Steve Jobs (Business Week, 1998).

\subsection{Hiper Kişiselleştirmeye İlişkin Arka Plan}

Literatür taraması çerçevesinde "hiper kişiselleştirme" konusunda sınırlı sayıda bilimsel çalışmanın olduğu görülmektedir. Bu çalışmalarda ise hiper kişiselleştirme kavramı üzerine araştırmacıların üzerinde ortaklaştığı net bir tanım olmadığı anlaşılmaktadır. Mevcut çalışmalar çerçevesinde hiper kişiselleştirme, özelleştirme ya da sıklıkla kişiselleştirme kavramı ile anılmıştır. Bazı yazarlara (Sunikka Bragge, 2009, s. 2) göre kişiselleştirme ve özelleştirme "kavramları arasında fark varken (Arora v.d., 2008; Gilmore ve Pine 1997; Kumar, 2009; Montgomery ve Smith, 2009), bazılarına göre ise kavramlar birbirinin yerine kullanılmaktadır (örn; Miceli v.d., 2007)" Bu bağlamda ilk önce literatürdeki bu kavramlara değinmek gerekmektedir.

Chellappa ve Sin'e (2005, s. 181-182) göre kişiselleştirme, “ürünlerin ve satın alma deneyiminin kişisel ve tercih bilgilerine dayalı olarak bireysel tüketicilerin zevklerine göre uyarlanması anlamına gelir. Bu nedenle, kişiselleştirme kritik olarak iki faktöre bağlıdır. Birincisi, satıcıların tüketici bilgilerini alma ve işleme yeteneği; ikinci olarak ise tüketicilerin bilgi paylaşma ve kişiselleştirme hizmetlerini kullanma istekliliğidir." Montgomery ve Smith'e göre (2009, s. 130) kişiselleştirme, "Tüketicinin davranışından veya işlemlerinden çıkarılan bilgileri kullanarak üretici tarafindan ürün ve hizmetlerin tüketici için uyarlanmasıdır." Kavramı kitle üzerinden ele alan Ashok Kumar, kişiselleştirmeyi tek bir pazar bölümünü hedefleyen "sınırlayıcı bir kitle durumu" olarak açıklar (2008, s. 536). Kişiselleştirmenin temel hedefi ise kullanıcıların ihtiyaçlarına ve bağlamlarına uygun, yüksek düzeyde odaklanmış, alakalı içeriği anlamak ve sunmaktır (Albert v.d.,2004'ten aktaran Ho, 2007, s. 41).

Geleneksel bir yöntem olarak ifade edebileceğimiz kişiselleştirme, "Müşteri özelliklerine dayalı olarak müşteri hakkında belirli varsayımlar yapmak için profil 
oluşturmada kullanılır ve ad, organizasyon, satın alma geçmişi ve benzeri gibi kişisel ve işlemsel bilgilere odaklanır. Bunun en yaygın örneği olarak bir e-postanın konu satırına bir müşterinin ilk adının dâhil edilmesi" (Medium, 2019) ya da "bir müşterinin satın aldığı bir Louis Vuitton el çantasına baş harflerini eklettirmesini istemesi gibi üretim süreci sırasında müşteri ve tedarikçi girdilerinin etkileşimidir. Özelleştirme ise tüketicilerin bireysel isteklerine bağlı olarak bir tedarikçinin ürün veya hizmetlerini değiştirme ve dolayısıyla bireysel olarak yaratma yeteneğini ifade eder" (Da Silveira v.d., 2001'den aktaran Rosenbaum v.d., 2019, s. 2-3).

Kişiselleştirme ve özelleştirme kavramlarına anlamca yakın başka kavramlarda söz konusudur. Bire bir pazarlama ve müşterileştirme bu kavramlar arasındadır. “Peppers ve Rogers'a (1997) göre bire bir pazarlama, bir işletmenin müşterilerini tanıyan ve müşterilere farklı davranması fikrine dayanan kişiselleştirilmiş pazarlamadır. Yazarlar kişiselleştirmeyi dört aşamalı bir süreç olarak kavramsallaştırır: I) potansiyel müşteriyi tanımlama; II) ihtiyaçlarını ve şirket için yaşam boyu değerini belirleme; III) onlar hakkında bilgi edinmek için müşterilerle etkileşim kurma; ve IV) ürünleri, hizmetleri ve iletişimleri bireysel müşteriler için özelleştirme" (Sunikka ve Bragge, 2009, s. 5).

Wind ve Rangaswamy'ye (2001, s. 15) göre, “Bir işletme, müşteriyle etkileşimler kurarak kendisine nasıl davranılmasını istediğini öğrenebilir. Böylece işletme, bu müşteriye diğer müşterilerden farklı davranabilir. Uygulandığı hâliyle bire bir pazarlama, tipik olarak firma tarafindan başlatılır (örneğin, bir müşteri tarafindan belirtilen geçmiş tercihlere dayalı olarak sigara içilmeyen bir otel odası sunmak). Bununla birlikte bire bir pazarlama, müşterilerin ne istediğini tahmin etmeye dayandığından, müşteriler belirli bir satın alma durumunda ne istedikleri konusunda net bir fikre sahip olmasalar bile özelleştirilmiş bir ürün sunulabilir (örneğin, sigara içen biri bazen sigara içilmeyen bir otel odasını tercih edebilir)."

Bire bir pazarlama ve kişiselleştirme kavramlarından geliştirilen müşterileştirme ise "alıcı merkezli bir stratejidir. Müşterilerin kontrolü altındadır ve onlar tarafindan başlatılır. Odak noktası, müşterilerin istediklerini kendileri için daha iyi belirlemelerine veya tanımlamalarına yardımcı olmaktır. Bu, şirketlerin kişiselleştirmeyi ve bire bir pazarlamayı dijital pazarlama ortamına uyarlamalarının bir yoludur. Müşterileştirme, müşterilerin ihtiyaçlarına en iyi şekilde uyan bir ürün veya hizmeti sunmak için "sipariş üzerine oluşturma" toplu özelleştirme sürecinden yararlanır. Aslında ürün üretilmeden satılmaktadır! Bunun aksine bire bir pazarlama ve kişiselleştirme zorunlu olarak müşteriler tarafindan başlatılmamakta veya onların kontrolü altında yürütülmemektedir. Daha da önemlisi, üretim ve tedarik zincirlerini pazarlama ile yakından bütünleştirilmemektedir. Bunun yerine, belirli 
müşterilerin ihtiyaçlarına uyması için çevrelerinde yerleşik bir ürün veya süreci değiştirmeye güvenirler" (Wind ve Rangaswamy, 2001, s. 15).

\subsection{Hiper Kişiselleştirme Nedir?}

Hiper kişiselleştirme bire bir pazarlama, özelleştirme, müşterileştirme ve özellikle de kişiselleştirme gibi bir dizi ilişkisel dijital pazarlamanın yapay zekâ tabanlı yeni bir evresidir. Bu bağlamda Todd Lebo (Ascend2, 2018) hiper kişiselleştirmeyi, "her kullanıcıya daha alakalı içerik, ürün ve hizmet bilgileri sunmak için yapay zekâ ve gerçek zamanlı verilerden yararlanarak kişiselleştirilmiş pazarlamayı bir adım öteye taşımak olarak açıklar." Yapay zekâ ve makine öğrenimini hiper kişiselleştirmenin önemli araçları olarak gören Annette Franz (2020) hiper kişiselleştirmeyi, kişiselleşmenin evrimselleşmesi olarak açıklar. Ona göre hiper kişiselleştirme, analitik odaklı veriye dayalı -hatta bununda ötesinde- bir kişiselleştirmedir. IBM'den Eddie Segal'in (2020) vurguladığı gibi hiper kişiselleştirme, pazarlamada müşteri deneyimini iyileştirmek için müşteri verilerinden yararlanan bir stratejidir: Hiper kişiselleştirmeyi kullandığınızda müşterilerle doğru zamanda iletişim kurabilir, özel olarak seçilmiş öneriler sunabilir ve böylelikle mevcut müşterilerle daha iyi etkileşim sağlar; aynı zamanda yeni müşteriler kazanabilirsiniz.

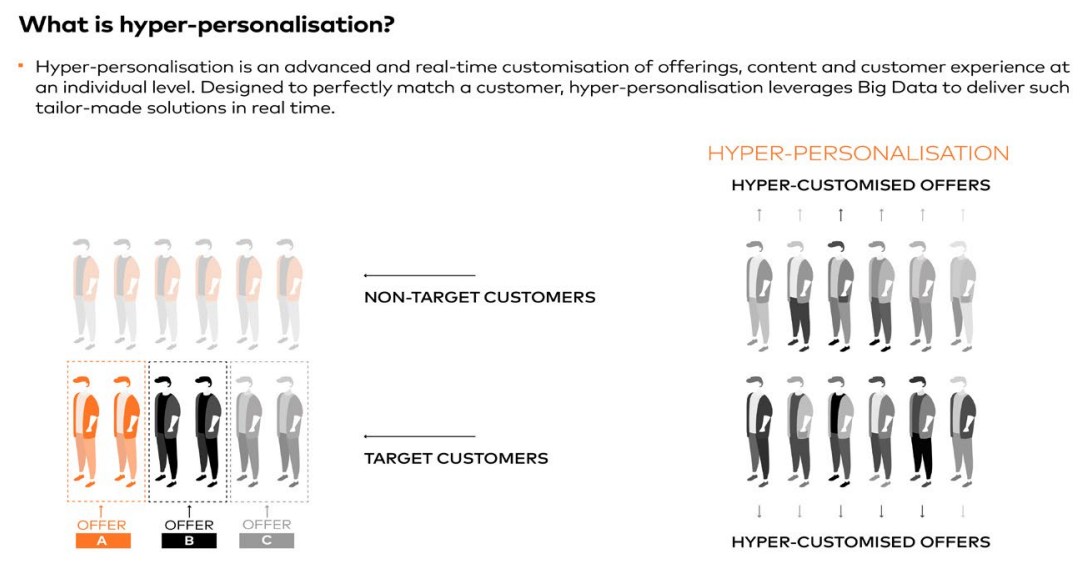

Şekil 1. Hiper Kişiselleştirme. Kaynak: (Dabrowski, 2020).

Hiper kişiselleştirme kavramını açıklamaya çalışan diğer yazarları şöyle sıralayabiliriz: 
Tablo 1. Hiper Kişiselleştirmeyi Tanımlayan Yazarlar

\begin{tabular}{|c|c|}
\hline Yazar(lar) & Tanım \\
\hline Jha Priyam (2019) & $\begin{array}{l}\text { "Hiper kişiselleştirme, her kullanıcıya daha alakalı içerik, ürün ve hizmet } \\
\text { bilgileri sağlamak için yapay zekâ ve gerçek zamanlı verilerden yararlan- } \\
\text { dığı kişiselleştirilmiş pazarlamanın daha gelişmiş bir adımıdır." }\end{array}$ \\
\hline $\begin{array}{l}\text { Stephanie } \\
\text { Mialki (2019) }\end{array}$ & $\begin{array}{l}\text { "Hiper kişiselleştirme, markaların son derece özelleştirilmiş bir pazar- } \\
\text { lama stratejisi oluşturması için birden çok kanaldan ve temas nokta- } \\
\text { sından çıkarılan davranışsal ve gerçek zamanlı verileri birleştirmesidir. } \\
\text { Böylelikle markalar, ürünlerini, hizmetlerini ve reklam içeriklerini mak- } \\
\text { simum alaka düzeyi ve dönüşüm potansiyeli ile her tüketiciye göre } \\
\text { uyarlamalara olanak tanır." }\end{array}$ \\
\hline $\begin{array}{l}\text { Chloe Annas } \\
\text { (2020). }\end{array}$ & $\begin{array}{l}\text { "Hiper kişiselleştirme, yapay zekâ, makine öğrenimi ve IoT (Nesnelerin } \\
\text { İnterneti) özellikli araç teknolojileri kullanılarak müşteri niyetlerini daha } \\
\text { ayrıntlı olarak yorumlanmasıdır. Bu gelişmiş teknolojilere sahip araçlar, } \\
\text { şirketlerin ilgili önerilerini ve deneyimlerini kullanıcılara çok geniş öl- } \\
\text { çekte sunabilmektedir." }\end{array}$ \\
\hline $\begin{array}{l}\text { Gilad Maayan } \\
(2020)\end{array}$ & $\begin{array}{l}\text { "Hiper kişiselleştirme, müşterilere daha özelleştirilmiş bilgiler veya öne- } \\
\text { riler oluşturmak ve sunmak için müşteri verilerinin kullanılmasıdır. Bu } \\
\text { özelleştirmeler, bireysel müşteri profillerine göre oluşturulmaktadır. } \\
\text { Profiller ise, tarama modelleri, satın alma geçmişleri, coğrafi } \\
\text { konum, demografik ve davranışsal bilgilerden elde edilen verilerin } \\
\text { kullanımından elde edilir." }\end{array}$ \\
\hline $\begin{array}{l}\text { Andy Kaiser } \\
\text { (2020) }\end{array}$ & $\begin{array}{l}\text { "Hiper kişiselleştirme de aşamasında müşteri bilgileri ve deneyimleri } \\
\text { bireysel olarak tanımlanır. Bu aşamada kişi, benzersiz müşteri deneyimi, } \\
\text { doğrudan hedefleme ve hiper bağlamsallaştırma için büyük veri, yapay } \\
\text { zekâ odaklı algoritmalar ve tahmine dayalı modellerden yararlanılarak } \\
\text { yönlendirilir." }\end{array}$ \\
\hline
\end{tabular}

Hiper kişiselleştirme, kişiye özel olması, bağlamsal içerikler sunması, kişiye göre en uygun zamanda gerçekleşmesi nedenleriyle kişiselleştirmeyi yeni bir seviyeye çıkarmıştır (Abbott Minasian, 2020, s. 3) Bu bağlamda, "Kullanıcılara bağlamsal olarak yüksek oranda hedeflenmiş ve kişiselleştirilmiş ürünler/hizmetler, indirimler, teklifler ve alakalı içerikler sunulur ve tüm bunlar, doğru kanalda doğru içerikle doğru zamanda doğru kullanıcıya ulaştırılır" (Mandeep, 2019). Hiper kişiselleştirme de oldukça önemli olan bağlam, müşterinin konumu, aracı (kanalı), etkileşim günü ve saati, ürün kategorisi, geçmiş marka etkileşimleri, satın almaları ve daha fazlası şeklinde olabilir (Franz, 2020). Böylelikle müşterinin ne yapmaya çalıştı̆̆ına ilişkin bir anlayış ortaya konulur ve buna göre de öneriler ya da eylemler oluşturulur (Abbott Minasian, 2020, s. 3).

Accenture'ın araştırmasına göre işletmelerin yanlış kişiselleştirme yöntemleri nedeniyle müşterilerin yüzde 48'i kaybedilmiştir. Bu sonuç bağlamında, "Kişiselleştirme neredeyse her işletme için öncelik hâline gelmiştir" (2018, s. 3). Daha önce 
de ifade edildiği gibi tüketicilerin yüzde 91'i, kendisini daha iyi tanıyan, hatırlayan, uygun teklifler ve öneriler sunan perakendecilerle alışveriş yapmak istemektedir (Accenture, 2018, s. 3). Epsilon'un, "Benim gücüm: Kişiselleştirmenin pazarlama performansı üzerindeki etkisi" (2018) adlı araştırması da benzer bir sonucu ortaya koyar. Bu araştırmaya göre markalar, müşterilerine başarılı kişiselleştirilmiş deneyimler sunduğunda tüketicilerin yüzde 80'inin satın alma olasılığı artmaktadır. Epsilon'dan Kevin Mabley (2018) yaptıkları araştırma bulgularını yorumlarken müşteriyi ayrıntılı tanımanın bir markanın kâr hanesi üzerinde doğrudan bir etkiye sahip olduğunu belirtir. Bilimsel çalışmalar da benzer sonuçları ortaya koyar. Hiper kişiselleştirmenin müşteri üzerindeki etkisine yönelik olarak yapılan "Hyper-personalization - fashion sustainability through digital clienteling" (Jain v.d.,2018) adlı bilimsel çalışmada hiper kişiselleştirmenin satın alma niyeti ile güçlü bir ilişkiye sahip olduğunu ortaya konulmuştur. Bir diğer bilimsel çalışma "Hyper-personalization, co-creation, digital clienteling and transformation" (Jain v.d., 2021) adlı makale de hiper kişiselleştirmenin, müşteri tutumunu önemli ölçüde etkilediği tespit edilmiştir.

\section{Kişiselleştirmede Öneri Motorları}

Geleneksel kişiselleştirme araçları sınırlı sayıda müşteri profili için tasarlanır. Bu tasarlanan profillerin her biri de bir müşteri kategorisini temsil eder. Müşteriler de bu kategorilerden uygun olan birine dâhil edilir. Fakat bu kişiselleştirme işleyişi her müşteri için her zaman doğru profili sunamamaktadır. Yapay zekâ tabanlı teknolojiler kullanılarak gerçekleştirilen kişiselleştirmelerde ise her bir müşterinin verileriyle genişletilebilir ve özelleştirilebilir ayrı ayrı profil bağlantıları oluşturulabilmektedir. Bu profillerin her biri de müşteriyi daha gerçekçi bir şekilde temsil eder ve böylelikle müşterinin gerçek ihtiyaçlarının karşılanma olasılığı daha yüksek hâle getirilmiş olur (Segal, 2020).

Yapay zekâ tabanlı hiper kişiselleştirme, kullanııı verilerinden yararlanır. Her bir kullanıcı için algoritmayı geçmiş ve gerçek zamanlı veriler ile besler ve ardından yapay zekânın analiz yapmasına izin verirsiniz, yapay zekâ her bir kullanııının ihtiyaçlarını öğrenir ve o kullanıcılara hiper kişiselleştirilmiş içerikler sunar. Web sitesinin bir parçası olarak yapay zekâ, görünmez bir satş̧ görevlisi gibi hareket ederek müşterilerin seçim yapmalarına ve satın alma olasılıkları en yüksek olan ürün ve hizmetleri bulmalarına yardımcı olur (Segal, 2020).

Kişiselleştirme işlemleri öneri sistemleriyle gerçekleştirilir. Çünkü öneri sistemleri çok güçlü kişiselleştirme araçlarıdır. Bu sistemler insanlara sevecekleri ancak kendi başlarına keşfetmeleri olası olmayan ögeleri gösterir; aynı zamanda doğru za- 
manda ve doğru sayfada ilgili ögeleri sunarak bir ziyaretçinin deneyimini iyileştirir (Arora, 2016). Söz konusu bu iyileştirmeyi kullanıcı profili bilgileri ve davranışsal eylem verilerinden sağlayan öneri sistemleri, "Verilerin farklı kaynaklardan toplandığı, veri kümelerinin saklandığı, ögelerle ilgili en alakalı bilgilerin filtrelendiği ve bir veri kümesindeki kalıpları keşfederek kullanıcılara sunulduğu bir süreçtir" (Tyagi, 2019). Kişiselleştirmeyi sağlayan öneri motorları, e-ticaret sitelerinde, çevrim içi web sitelerinde, mobil uygulamalarda, sosyal medya platformlarında yaygın olarak kullanılmaktadır. Hiper kişiselleştirilmiş içerikler sunan yapay zekâ tabanlı öneri motorları özellikle video akış platformlarında son dönemde popüler bir yaklaşım olarak tercih edilmektedir:

Tasarladığı öneri motoruyla abonelerine hiper kişiselleştirilmiş içerikler sunan şirketlerden biri Netflix'dir. Shabana Arora'ya (2016) göre, en iyi öneri motoruna sahip olmanın önemini bilen Netflix, algoritmasını optimize etmek için yatırımlarını bu alana kaydırmaktadır. Ayrıca Netflix, 2009 tarihinde algoritmalarının verimliliğini artrrabilecek herhangi bir araştırma ekibine bir milyon dolarlık ödül verileceğini duyurduğu bir yarışma da düzenlemiştir. Birçok yazıııcı ekibin katılım sağladığı Netflix'in büyük ödüllü bu yarışması, içerik ve keşif sistemlerinin geliştirilmesinde kayda değer bir öneme sahiptir (Arora, 2016). Bu anlamda Netflix'in büyük yatırımlar yapth̆̆ ve sürekli olarak geliştirdiği öneri motorunu detaylı olarak incelemek, şirketin kişiselleştirme yaklaşımını anlama adına önem arz etmektedir.

\section{Netflix ve Hiper Kişiselleştirme}

Online televizyon pazarına 1997 yılında giren Netflix, Reed Hastings ve yazılım yöneticisi Marc Randolph tarafindan internet üzerinden film kiralama hizmeti sunmak amacıyla kurulmuştur. 2007 yılında ise Netflix, televizyon dizilerini ve sinema filmlerini izleyicilerin kişisel cihazlarından anında izlemelerini sağlayan yayın özelliğini kullanıma sunmuştur. Netflix kısa sürede küresel bir şirket hâline gelmiş ve 2016 senesinde New York borsasına 8.83 milyar dolar gelir elde ettiğini bildirmiştir (Kapır, 2019, s. 220). İstatistik portallarından Statista'nın verilerine göre Netflix, 2021'in ilk çeyreği itibarıyla dünya genelinde toplam 207.64 milyon aboneyle dünyanın en büyük video akış hizmeti sağlayıcısıdır (Statista, 2021).

Netflix'in uluslararası başarısı Jha Priyam'ın da belirttiği gibi, büyük ölçüde kullanıcılarına son derece kişiselleştirilmiş bir deneyim sunmasından kaynaklanmaktadır. Site faaliyetlerinin yüzde 75'inden fazlası kişiselleştirme motorlarından gelen içeriklerinden oluşmaktadır (Priyam, 2019). Netflix öneri motoru ise yapay zekâ tabanlı makine öğrenimi algoritmaları tarafindan desteklenmektedir. Buna göre Netflix, geleneksel olarak abonelerin hizmeti nasıl kullandığına dair bir grup veri 
toplar. Bu veri yığını üzerinden de yeni bir makine öğrenimi algoritması çalıştırır (Chandrashekar v.d.,2017). Bu algoritma da abonelerine kişiselleştirilmiş içerikler tavsiye eder. Sistem etkileşime bağlı olarak kendi içinde tavsiyelerini sürekli olarak ölçer ve denetler. Sonunda da abonenin beklentilerini karşılayacak hiper kişiselleştirilmiş içerikler sunar. Netflix, makine öğrenimi teknolojisini kullanan bu sistemine "Meson" adını vermiştir:

\begin{abstract}
Netflix'te amacımız, ne izlemek istediğinizi tahmin etmektir. Bunu yapmak için, her gün çok sayıda Makine Öğrenimi (Machine Learning) iş akışını çalıştırıyoruz. Bu iş akışının oluşumunu desteklemek ve kaynakları verimli kullanmak için de Meson'u yarattk. Meson, heterojen sistemlerde genel amaçlı bir iş akışı düzenleme ve zamanlama programıdır. Meson, video önerilerini yönlendiren, kişiselleştirme algoritmalarını oluşturan, öğreten ve doğrulayan makine öğrenimli çeşitli düzenlerin ardışık yaşam döngüsünü yönetir (Netflix, 2016).
\end{abstract}

Meson Sistemi, şirketin "video önerilerini yönlendiren, kişiselleştirme algoritmaları oluşturan, eğiten ve doğrulayan" birden fazla makine öğrenimi hatt için bir trafik polisi görevi görmektedir. Dolayısıyla Meson, bir medya markasının sofistike yeni yetenekler sağlamak için yapay zekâ ve makine öğrenimi tabanlı inşa edilen kişiselleştirme sistemleri için iyi bir örnek olarak karşımıza çıkar (Entefy, 2018). ${ }^{1}$

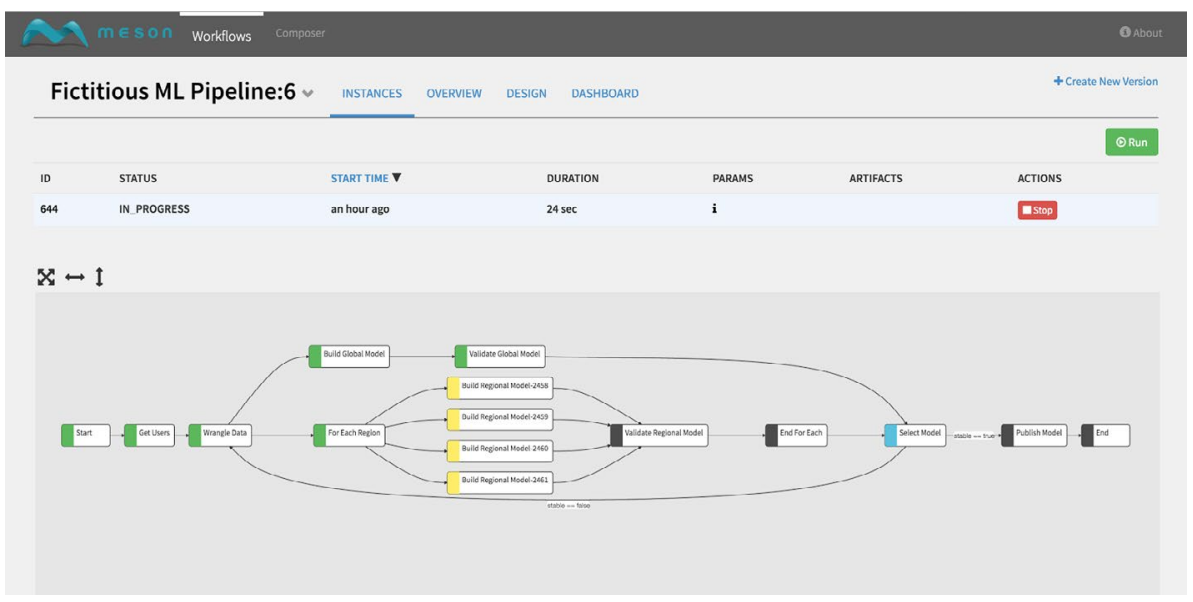

Şekil 2. Meson'un Arayüzü. Kaynak: (Netflix, 2016).

Netflix'in ürün sorumlusu Neil Hunt ve Gomez Uribe (McAlone, 2016), kişiselleştirme ve önerilerin birleşik etkisinin Netflix'e yılda bir milyar dolardan fazla tasarruf sağladığını ifade eder. Onlara göre Netflix'in tavsiye motoru, abonelere

\footnotetext{
${ }^{1}$ Netflix'in yazılım mühendisleri, Meson'u çok teknik detaylarla şu yazıda ele almıştır: Bkz: (Netflix, 2016).
} 
ilgi çekici içerikler sunarak abonelerin platform üyeliğini iptal etmesinin önüne geçen önemli bir araçttr. Nathan McAlone'nun deyişiyle, “Netflix, kişiselleştirilmiş öneri motoru kullanmasaydı, hizmetini bırakan abonelerden her yıl bir milyar dolar veya daha fazla kaybetme durumu ile karşı karşıya kalırdı" (2016).

2014'ün başlarında Netflix, kendi ana sayfasındaki ve dizinlerdeki görsellerin abonelere etkilerini ölçen bir dizi araştırma yapmıştır. Netflix'in Kreatif Direktörü Nick Nelson (2016), bu araştırmaları abonelerin iyi bir Netflix deneyimine nasıl yardımcı olunacağını öğrenmek için yaptıklarını ifade eder. Bu tüketici araştırmasına göre Netflix'in sayfasında bulunan içerik görüntüleri kişinin izleme kararında çok önemli bir etkiye sahiptir. Ayrıca bu araştırmalarda abonelerin Netflix'teyken kendilerine sunulan her bir içerik için ortalama 1.8 saniye harcadıkları tespit edilmiştir. Araştırma sonuçları sonrası Nelson, bir görüntünün bir üyenin içerik bulması üzerindeki güçlü etkisini anladıklarını ve kullanıcıların ilgisini çekmek için sahip oldukları zamana şaşırdıklarını belirtmiştir: "Genel olarak, 90 saniye içinde bir üyenin dikkati çekilmez ise muhtemelen o üyenin ilgisini kaybedilebileceğimizi ve başka bir faaliyete geçeceğini biliyoruz. ...Sonuçta, insan beyni görüntüleri 13 milisaniye ${ }^{2}$ kadar kısa bir sürede işleyebilir" (Nelson, 2016). Bu bağlamda Netflix şirketi kişiselleştirme sisteminin hayati önemini kavramış ve öneri sistemlerini bu bilgiler ışığında şekillendirerek kapsamlı bir şekilde kullanmayı önceliği hâline getirmiştir.

\subsection{Netflix'in Hiper Kişiselleştirme Sistemi Nasıl Çalışır?}

Netflix kataloğunda bulunan binlerce içeriğin kompakt ve etkili sunum özellikleri göstermesi şirket için kritik öneme sahiptir. Bunun için Netflix makine öğrenimi modellerini kullanır. Netflix'teki işlevsel fonksiyonları (medya dosyaları ve bunun yanı sıra tür etiketleri, özetler ve benzeri başlık meta verileri) girdi olarak kullanan makine öğrenimi teknolojileri elde ettikleri verilerle kullanıcı deneyimini en üst seviyeye çıkarır. Bu anlamda Netflix deneyimini başarılı kılan ve tanımlayan temel faktörleri şu şekilde sıralayabiliriz: Optimize edilmiş bir kullanıcı arayüzü, anlamlı kişiselleştirilmiş öneriler, verimli akış ve geniş bir içerik kataloğu (Netflix, 2018).

\footnotetext{
${ }^{1}$ Nelson'un burada atıf yaptğı süre bilimsel bir araştırmaya dayanmaktadır. Massachusetts Teknoloji Enstitüsü (MIT) sinirbilimcileri, beynin görülen görüntülerin anlamın 13 milisaniye kadar kısa bir sürede tanımlayabildiğini keşfetmişlerdir (Trafton, 2014).
} 


\section{NETFLIX}

Oturumu Kapat

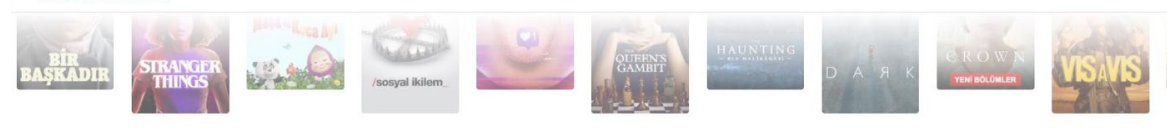

ferhat için kişiselleştirme yapılıyor

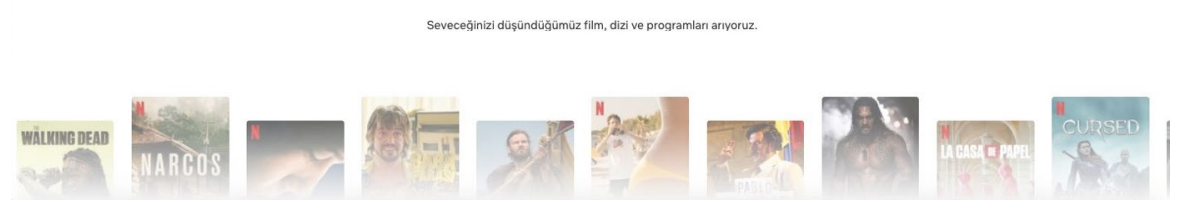

Şekil 3. Netflix'te Kişiselleştirmenin İlk Adımı

Netflix'in makine öğrenimi ve öneri sistemi mühendisleri Chris Alvino ve Justin Basilico (2015), Netflix'in kişiselleştirme yaklaşımını ve öneri sistemini şu sözlerle anlatirlar:

Büyük ölçüde kişiselleştirme yaklaşımımız, abonelerimizin izleyecek yeni bir şey bulmalarına yardımcı olmaktır. Biz buna keşif diyoruz. Bununla birlikte, bir üyenin bir şovun sonraki bölümünü izlemesini veya normalde tavsiye alanı dışında kalan geçmişte izlediği bir şeyi yeniden izlemesini de kolaylaştırmak istiyoruz. İçerik izleme önerilerimizin, üyelerimizin zevklerine uygunluğu açısından doğru olmasını istiyoruz, ancak aynı zamanda önerilerin çeşitli olmaları da gerekiyor. Dolayısıyla bir üyenin ilgi alanlarına odaklanıyoruz. Ayrıca üyelerimizin yeni ilgi alanları keşfetmesine ve sahip olduğumuz içerik genişliği de vurgulayabilmek istiyoruz (Alvino Basilico, 2015).

Netflix'in hiper kişiselleştirme amaçlı makine öğrenimi iş akışı yönetimi, farklı başlık özellikleriyle çalışmaktadır. Her bir başlık kendi içinde Netflix'in kişiselleştirme işlevine benzersiz katkılar sağlar. Bu başlıklardan belirleyici etkiye sahip olanları şu şekilde sıralamak ve açıklamak mümkündür:

\subsubsection{Satir Sinıflandırması}

Bir üyenin Netflix'in öneri sistemiyle ilk etkileşimi, oturum açıldıktan sonra karşısına çıkan ana sayfayla temasıdır. Çünkü ana sayfanın birincil işlevi, her üyenin beğeneceği, izleyeceği bir şeyi kolayca bulmaya yardımcı olmak ve abone hakkında veriler toplamaktır. Buna göre Netflix'in ana sayfası, yatay ve dikey sıralar hâlinde düzenlenmiş içeriklerle yapılandırılmıştı. Aboneler o satırlarda yer alan çok fazla sayıdaki videoları görmek için yatay olarak veya dikey olarak kaydırma yapabilirler (Alvino Basilico, 2015). 
Kişiselleştirme yaklaşımımızın önemli bir parçası, ana sayfada görüntülenecek içeriklerin nasıl seçileceği, satırların videolarla nasıl doldurulacağı ve izlenecek içeriğin sınırlı sayfa aralığında nasıl düzenleneceği ya da görüntüleneceğidir. Satırlarda video içeriklerini sınıflandırmanın doğal bir yolu, türe ve alt türlere veya yayın tarihi gibi diğer video meta veri boyutlarına göredir. Elbette, bu sınıflandırmanın arka arkaya videolar arasındaki ilişkinin yalnızca meta verilerden kaynaklanması gerekmez, ayrıca davranışsal bilgilerden (örneğin iş birliğine dayalı filtreleme algoritmalarından) bir üyenin izleyebileceğini düşündüğümüz videolardan ve hatta gruplardan video içerik sınıflandırmaları oluşturulabilir (Alvino Basilico, 2015).
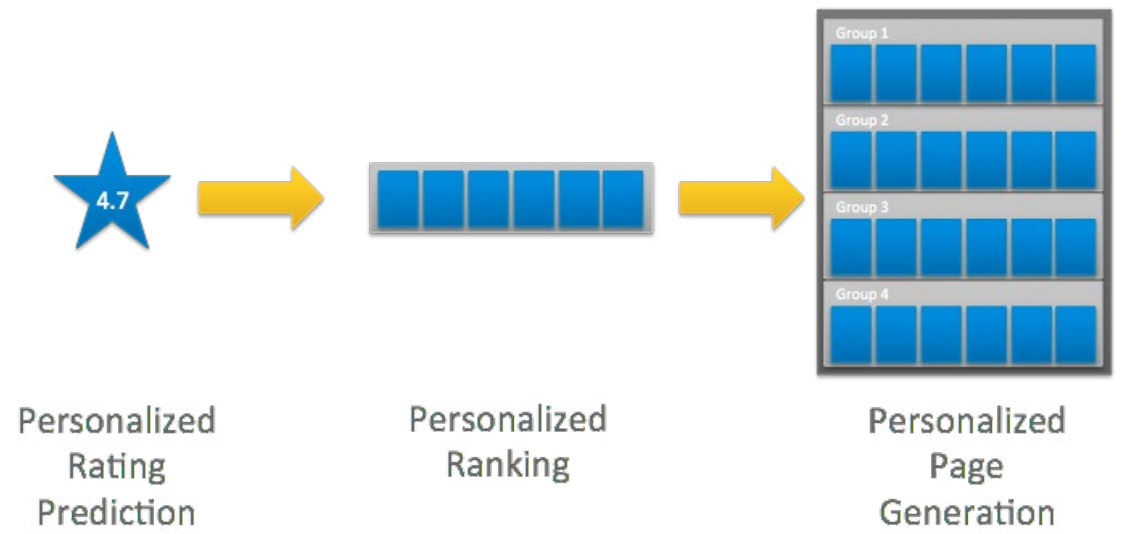

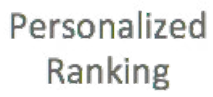

Pansonalized

\section{Personalized Page \\ Generation}

Şekil 4. Netflix'in Kişiselleştirme Evrimi. Kaynak: (Alvino ve Basilico, 2015).

Netflix'in mühendisleri Alvino ve Basilico'ya (2015) göre algoritmik olarak iyi bir kişiselleştirilmiş ana sayfa oluşturmak, bir üye için alakalı olabilecek binlerce videodan ve her biri değişken sayıda video içeren on binlerce potansiyel satırdan cihaz başına bir sayfa oluşturmak anlamına gelir. Bu eksende programlanan Netflix'in sayfa algoritması da binlerce değişken satır aralığındaki video içeriklerini, her bir üye için yaklaşık 10-40 satır aralı̆ında sınırlandırarak hiper kişiselleştirir.

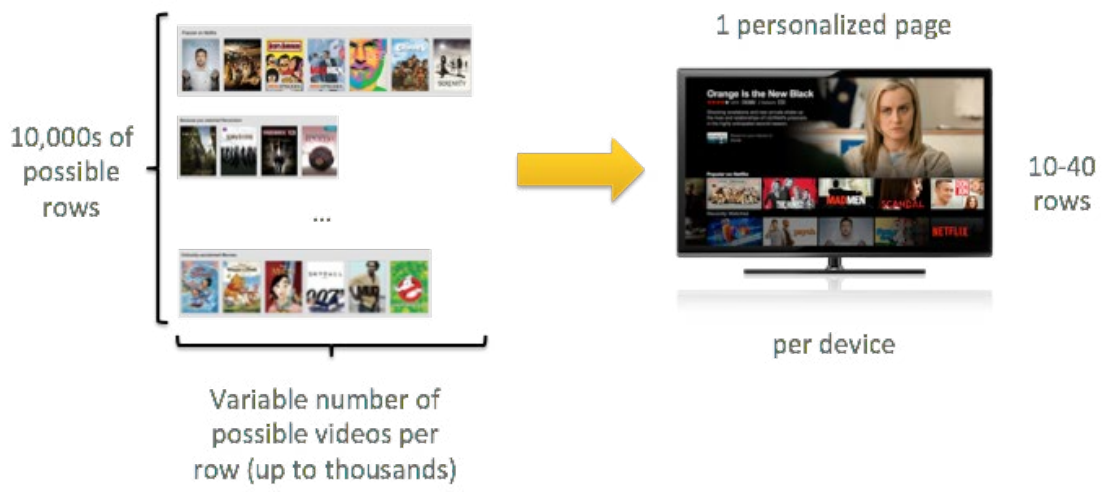

Şekil 5. Satır Oluşturma Sistemi. Kaynak: (Alvino ve Basilico, 2015). 
Her bir teknolojik cihazın, tüm ana sayfayı ve video satır sayısını sınırlayabilen farklı donanım özelliklerine sahip olduğunu vurgulayan Alvino ve Basilico (2015), bir kişiselleştirilmiş öneri sisteminin bir sayfa oluşturma sürecinde video, satır sayısı, bir satırın minimum ve maksimum uzunluğu, belirli satırların gerekli olup olmadığı gibi çeşitli kısıtlamaların farkında olması gerektiğini ifade ederler. Bu bağlamda ilk satırın "İlemeye Devam Et" (varsa), ardından "En Çok Tercih Edilenler" (varsa), ardından "Netflix'te Popüler" ve sonra gelen kişiselleştirilmiş beş tür satırı örneklerinde olduğu gibi Netflix'in algoritmik içerik motorunun sayfa oluşturmada belli kurallara dayanan bir yaklaşımı vardır. Mühendisler bu yaklaşıma "navigasyon modellemesi" adını verirler. Navigasyon modellemesinin önemi abonelerin dikkatini çekecek öncelikli görüntülerin konumunu ayarlamasıdır. Alvino ve Basilico (2015), abonelerin yataydan ziyade dikey tarama yapma olasılığının daha yüksek olduğunu ifade ederler. Bu da sol üstte sunulan videoların görüntülenme olasılığının çok daha yüksek olduğu anlamına gelir. Dolayısıyla kişiye özel en alakalı içerikleri, en yüksek görülme olasılığı olan sol üst köşelerdeki konumlara yerleştirmek, bir üyenin izlemekle alakalı içerikler bulma süresini kısaltacaktır.

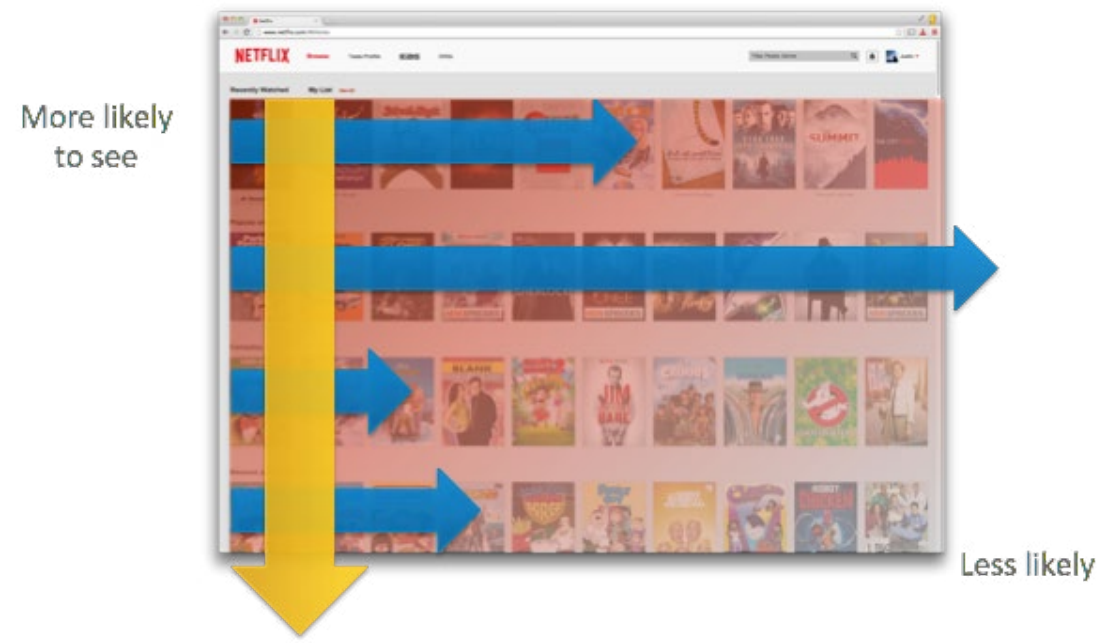

Şekil 6. Kişiye Özel Satır Sıralaması. Kaynak: (Alvino ve Basilico, 2015).

\subsubsection{Resimlerin Önemi ve Oluşum Süreci}

Netflix'in diğer makine öğrenimi mühendisleri Ashok Chandrashekar ve diğerleri (2017), Netflix'in kişiselleştirmedeki ana hedefinin, binlerce içerik başlığını kapsayan bir katalogda her üyenin önüne, doğru zamanda doğru başlıkları göstermek olduğunu ifade ederler. Bu başlık önermenin Netflix için oldukça mühim olduğunu söyleyen mühendisler, "Bir başlığın izlenmeye değer olduğuna sizi nasıl ikna 
edebiliriz?" sorusundan hareket ederek abonelerin ilgisini çekebilecek içeriklere ve görüntülere odaklandıklarını açıklarlar.

Netflix'in mühendislerine göre (Chandrashekar v.d., 2017), bir içeriğin bir üyenin ilgisini yakalaması -etkileşim sağlaması- Netflix'in hiper kişiselleştirme algoritmasının başlaması adına kapıdan ilk giriştir. Abonenin ilgisini çeken içerik, "görselde gördüğü yıldız bir oyuncu olabilir, araba kovalamacası gibi aksiyon içeren bir an da olabilir ya da bir filmin veya TV şovunun özünü yansıtan dramatik bir sahne de olabilir." Mühendislere göre sonraki süreç onlar için daha basittir. Buna göre ana sayfada abonenin ilgisini çeken içeriksel görsele "yakın" yeni görseller aboneye sunulur. Böylelikle yeni deneyimlere olanak sağlanır. Bir görselin bin kelimeye bedel olduğunu açıklamalarında özellikle vurgulayan veri mühendisleri, Netflix'te her abone için kişiselleştirilebilecek 100 milyondan fazla farklı görsel içerik bulunduğunu belirtirler. Bu içerikleri oluşturan sanatçı ve tasarımcılardan oluşan Netflix ekipleri, görüntüleri seçecek kişiselleştirme algoritmalarını da dikkate alırlar (Chandrashekar v.d., 2017). Örneğin Stranger Things (2016-) dizisinin her biri kişiselleştirme algoritmaları tarafindan oluşturulan farklı ekran görüntüleri şöyledir:
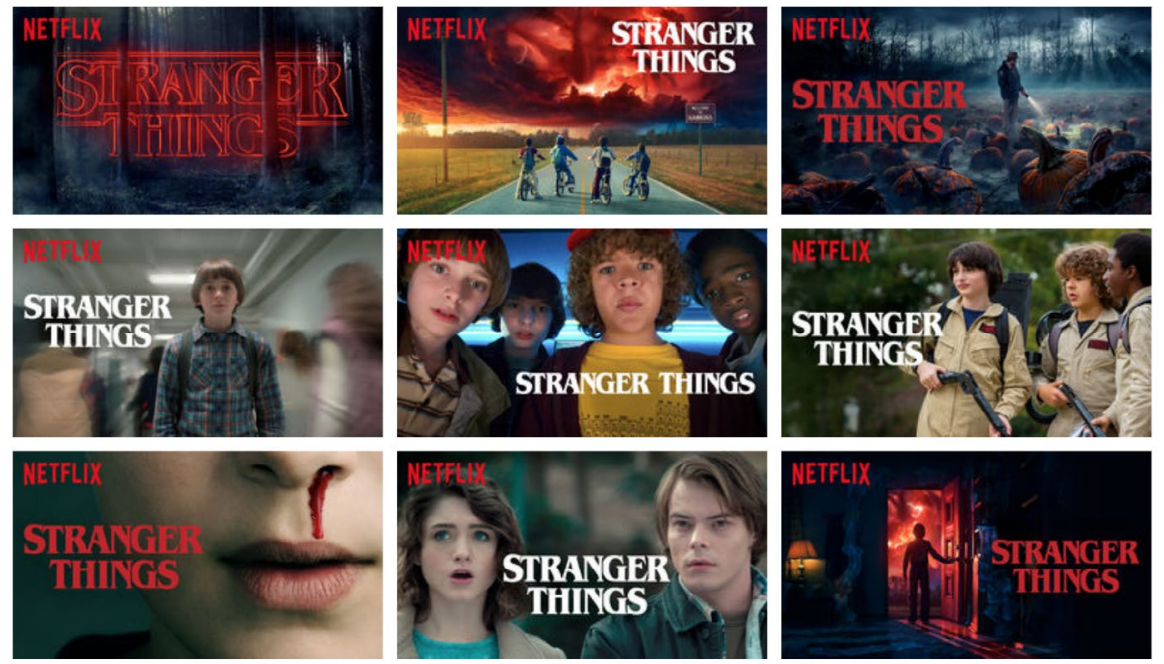

Şekil 7. Stranger Things İçeriğinin Farklı Tasarımları. Kaynak: (Chandrashekar v.d.,2017).

Chandrashekar ve diğerlerinin (2017) ele aldığı diğer bir örnek Good Will Hunting (1997) filmidir. Bir üyenin farklı tür ve tema tercihlerine bağlı olarak Good Will Hunting filminin ekran görüntüsü aşağıdaki gibi kişiselleştirilmiştir. Buna göre Netflix içeriklerinden pek çok romantik film izlemiş bir kişi için algoritma, Matt 
Damon ve Minnie Driver'ın yer aldığı bir afiş tasarımıyla filmin ekran görüntüsünü tasarlarken aynı algoritma Netflix'te çok sayıda komedi içeriği izlemiş bir üye için ise komedyen Robin Williams'ın yer aldığı bir afiş görüntüsü tasarlamıştır.
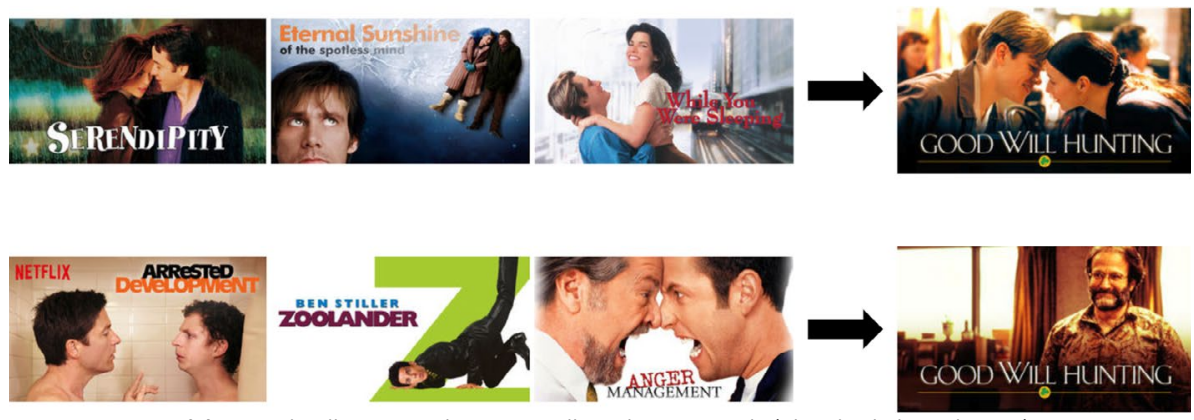

Şekil 8. Good Will Hunting Filminin Kişiselleştirilmesi. Kaynak: (Chandrashekar v.d.,2017).

Mühendisler, oyuncu kadrosunun kişiselleştirmeyi nasıl etkilediğini ise başrollerinde Uma Thurman ve John Travolta'nın olduğu Oscar ödüllü Pulp Fiction (1994) filmi örneği üzerinden anlatırlar. Şekil 9'da görüldüğü üzere, Uma Thurman’ın birçok filmini izleyen bir üye için Pulp Fiction filminin görüntü tasarımı, Uma Thurman'ın fotoğrafiyla kişiselleştirilmişken John Travolta içerikli filmleri izleyen bir üye için ise aynı film, John Travolta'nın yer aldığı görsel bir tasarımla sunulmuştur. Mühendislere göre aboneler, bu kişiselleştirmiş tasarımlara muhtemelen olumlu yanıt vereceklerdir (Chandrashekar v.d., 2017). Dolayısıyla bu sistemin iyi işlemesi Netflix'in aboneleri hakkında çok fazla veri toplamasına bağlıdır.
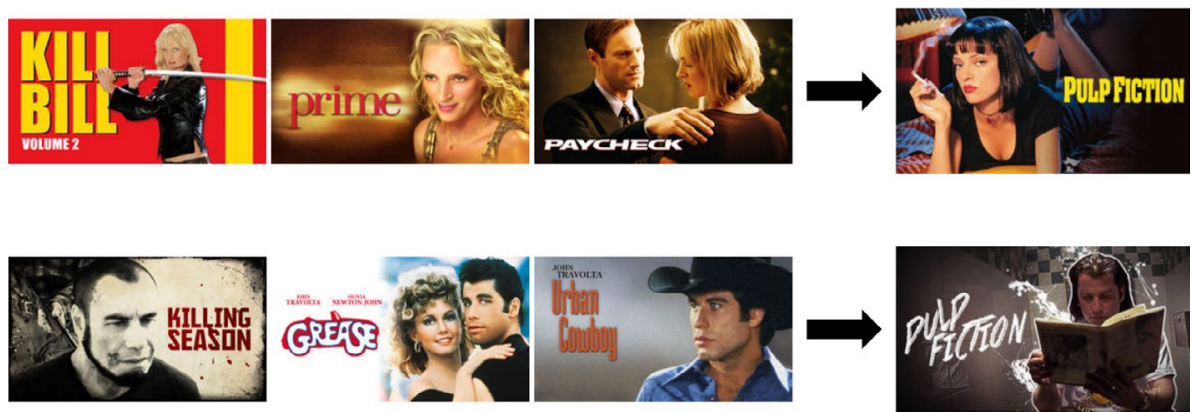

Şekil 9. Pulp Fiction Filminin Kişiselleştirilmiş Görselleri. Kaynak: (Chandrashekar v.d.,2017).

\subsubsection{Görsel Resimlerin Testleri}

Netflix'in tüketiciler üzerine yapmış olduğu araştırmalardan bir diğeri de A/B testidir. Abonelere aynı içeriğin farklı ekran görüntü tasarımlarının sunulduğu ve etkileşiminin ölçüldüğü (tıklama oranı, toplam oynatma süresi, kısa süreli hareket ettirme fraksiyonu, görüntülenen içeriğin fraksiyonu (içerikte ne kadar ilerlenildiği vb.)) bu test sonucunda Netflix şirketi, farklı görseller kullanarak izleyici ev- 
renini genişletebileceğini ve katılımı artırabileceğini gerçek anlamda görmüştür. (Netflix, 2016). Nelson (2016) bu durumu "resmin gücü" olarak açıklar: "İmgeleme güçlü bir şeydir. İnsanları pek çok farklı şekilde yönlendirme yeteneğine sahiptir. Araştırmamızın sonuçlarına göre, bir görüntünün insanları güçlü ve doğru şekilde yönlendirebileceği açıktır."

Nick Nelson (2016), A/B test sonuçlarına göre bir içeriği temsil eden en iyi görselleri kullanmak için yapılması gerekenleri örnekler üzerinden dört başlıkta toplamıştır:

1. Duyguları kullanmak önemlidir: A/B test sonuçlarına göre karmaşık duygulara sahip yüz görselleri, metanetli veya iyi huylu ifadelerden daha iyi performans göstermiştir. Buna göre içeriği temsil eden bir görselde bir dizi duygu ifadelerini görmek, insanları o hikâyeyi daha fazla izlemeye zorlar. Bunun nedeni, karmaşık duyguların bir içeriğin tonu veya hissi ile ilgili kullanıcılara zengin bilgi aktarmasıdır. Bunu, aşağıdaki Unbreakable Kimmy Schmidt (2015-2019) dizisinin görsellerinde görmek mümkündür. A/B testine göre, karışık yüz ifadelerinin yer aldığı yeşil okla işaretli içerik görseli, diğer görsellere göre daha fazla etkileşim almıştır.
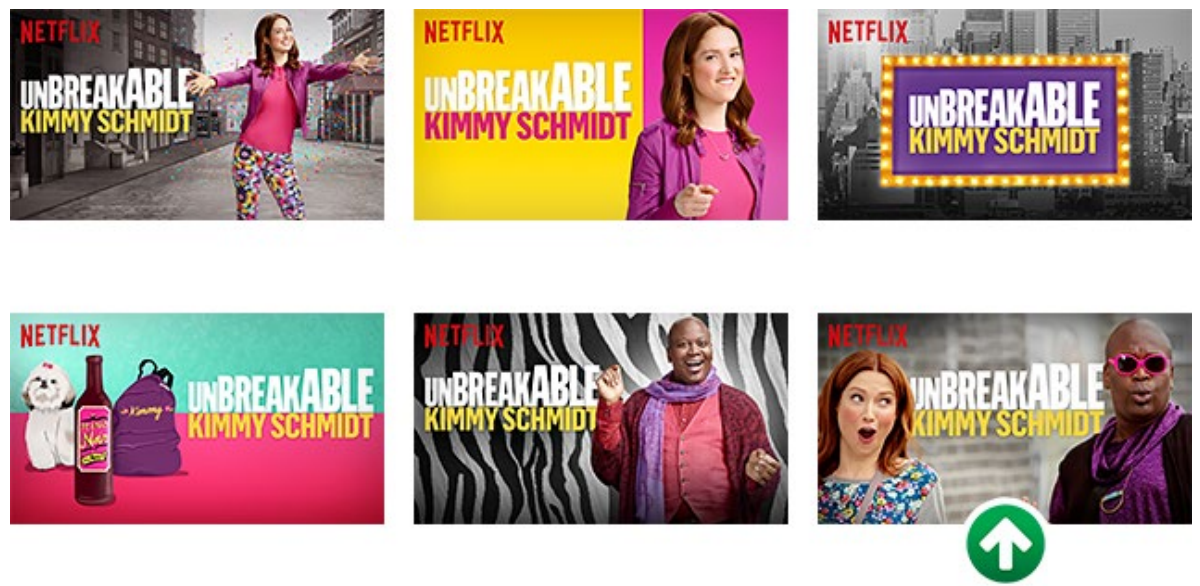

Şekil 10. Unbreakable Kimmy Schmidt İçeriğinin Görselleri. Kaynak: (Nelson, 2016).

2. Hikâyeler ülkeler arasında dolaşabilir ancak bölgesel nüanslar güçlüdür: Kültürler arasında bağlantılı içeriklerin görsellerinde yerel farklılıkları dikkate almak önemlidir. Bu sonucu, sekiz kişinin telepatik olarak birbirlerinin hayatını deneyimleyebildiği uluslararası oyunculara sahip Netflix'in Sense8 (2015-2018) dizisinin görsellerinde bulabiliriz. A/B testinde abonelerin dizinin görselleriyle olan etkileşimi, ülkeler ve kültürler arasında farklılık göstermiştir. Böylelikle bölgesel farklılıkları dikkate alarak görseller hazırlamanın önemli olduğu anlaşılmıştır. 


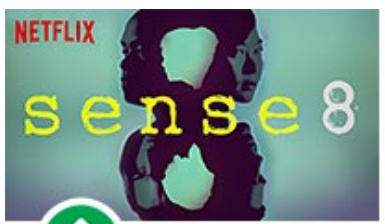

Top in Germany

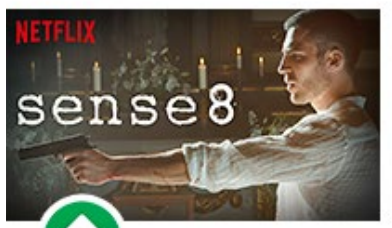

Top in UK

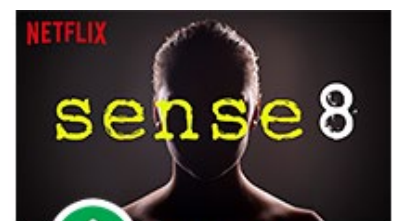

Top in Brazil

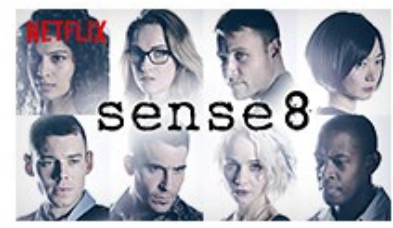

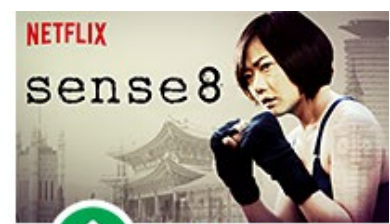

Top in US

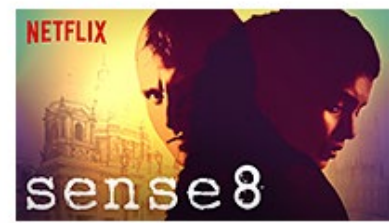

Şekil 11. Sense8 İçeriğinin Görselleri. Kaynak: (Nelson, 2016).

3. Tanınır karakterleri kullanmak önemlidir: Araştırma boyunca görünür ve tanınır karakterlerin (özellikle kutuplaştırıcı olanların) görsellerde kullanılması daha fazla etkileşim sağladığı anlaşılmıştır. Hem çocuklarda hem de yetişkinlerde aboneler, özellikle aksiyon türlerindeki kötü karakterli görsellere şaşırtıcı derecede olumlu yanıt vermişlerdir. Örneğin, Dragons: Race to the Edge (2013-2018) için oluşturulan aşağıdaki içerik görsellerinde kötü karakterlerin yer aldığı iki görüntü (yeşil okla belirtilen) önemli ölçüde diğerlerine göre daha iyi performans (etkileşim) sergilemiştir.
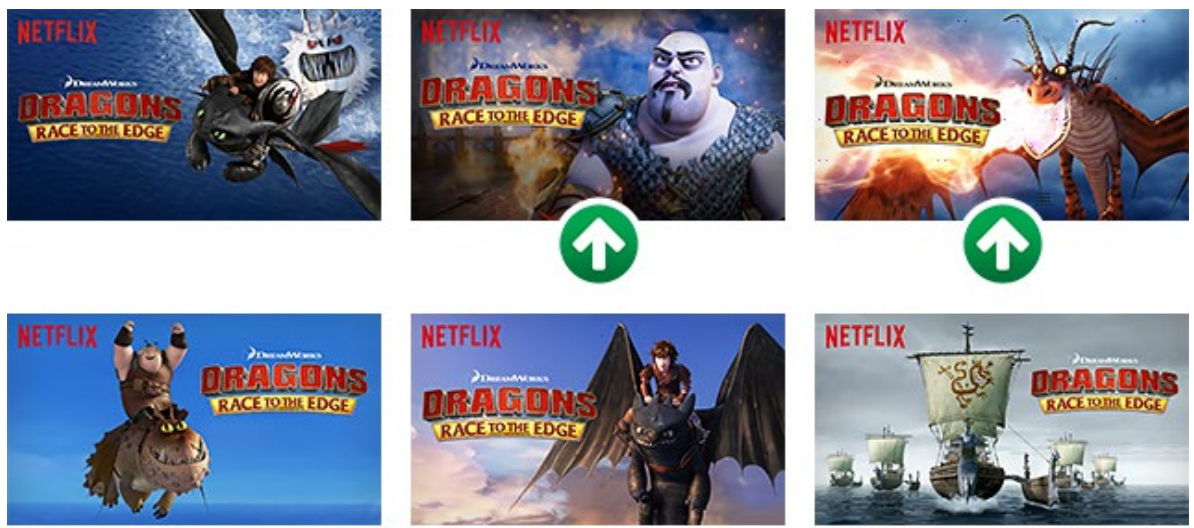

Şekil 12. Dragons: Race to the Edge İçeriğinin Görselleri. Kaynak: (Nelson, 2016).

4. Oyuncu seçiminde azlık iyidir: Araştırmaya göre bir görselin üç kişiden fazla kişiyi içermesi etkileşimi önemli ölçüde düşürdüğü anlaşılmış ve küçük ekranlarda tercihte bulunan Netflix abonelerinin kararlarında etkili olmadığı tespit edil- 
miştir. Bunun nedeni birden fazla karakter tasarımlı görsellerin küçük ekranlarda oldukça karmaşık görünmesidir. Testlerde elde edilen bu bilgi Netflix'in kreatif kararlarını doğrudan etkilemiştir. Aşağıdaki Orange is the New Black (2013-2019) dizisinin görsel tasarımlarında görüldüğü üzere, birinci sezondan sonra kişiselleştirmeler tek bir karakter üzerinden düzenlenmeye başlanmıştır.

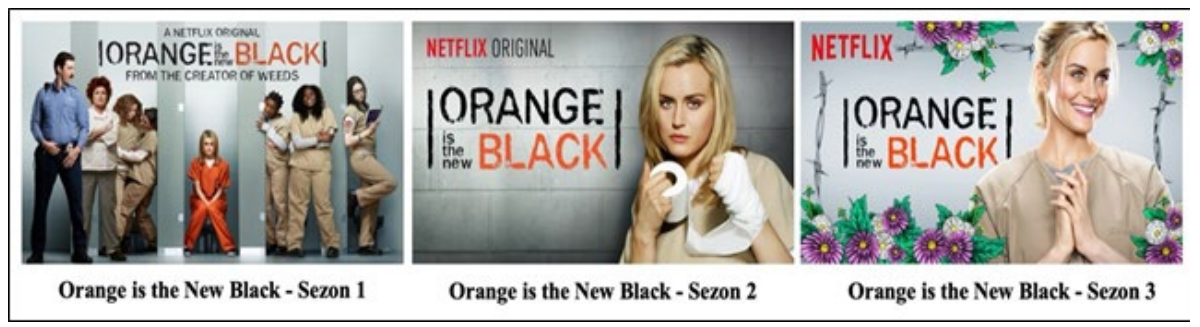

Şekil 13. Orange is the New Black İçeriğinin Görselleri Kaynak: (Nelson, 2016).

\subsection{Hiper Kişiselleştirmede Yararlanılan Veriler ve Modeller:}

Müşteriyle yüz yüze gelen her işletme, kullanıcıları hakkında farklı noktalarda veriler toplamaktadır. Genel olarak çevrim içi video akış sitelerinin kullanıcılardan topladığı ortak veri noktaları şunlardır (Priyam, 2019):

Tablo 2. Çevrim içi Video Akış Sitelerinin Topladığı Ortak Veriler (Priyam, 2019)

\begin{tabular}{|l|l|l|}
\hline \multicolumn{1}{|c|}{ Kullanıcı Özellikleri } & \multicolumn{1}{|c|}{ Davranışsal Nitelikler } & Geçmiş Satın Alma Verileri \\
\hline Yaş & Arama & Sepete ekle \\
\hline Konum & Medya Kategorisi Filtreleri & Satın Alma Tarihi ve Saati \\
\hline Cinsiyet & $\begin{array}{l}\text { Medya Türü Filtreleri } \\
\text { (Ses / Filmler) }\end{array}$ & Abonelik Yenilendi \\
\hline Üye Sınıflandırması & Fragman Oynandı & $\begin{array}{l}\text { Satın almak için kullanılan } \\
\text { cihaz }\end{array}$ \\
\hline Cihaz & İzleme listesine ekle & Ödeme şekli \\
\hline İşletim sistemi & İncelendi / Derecelendirildi & Sanatçı / Film Tercihi \\
\hline İsim & Akış Sayımı / Sıklı̆ıı & \\
\hline & Dil Tercihi & \\
\hline & Oynatma listesine ekle & \\
\hline
\end{tabular}

Netflix'in kişiselleştirme veri bilimi mühendislerinden Xavier Amatriain ve Justin Basilico'ya (2012) göre, veri ölçümleri ve bu amaç doğrultusunda ilgili testlerin bolluğu, Netflix'in veri odaklı bir organizasyon yürütmesine olanak tanır. Onlar bu organizasyona "Tüketici (Veri) Bilimi" adını verirler:

Genel olarak "Tüketici Bilimi” yaklaşımımızın temel amacı, üyeler için etkili bir şekilde yenilik yapmaktır. Bizim için gerçek başarısızlık, yenilik yapamamaktır. 
Fikirleri hızlı, ucuz ve objektif bir şekilde değerlendirmemize olanak tanıyan bir inovasyon kültürü için çalışıyoruz. Ve bir şeyi test ettiğimizde, neden başarısız olduğunu veya başarılı olduğunu anlamak isteriz. Bu da abonelerimiz için hizmetimizi iyileştirme ana hedefine odaklanmamızı sağlar (Amatriain Basilico, 2012).

Netflix'in veri bilimcileri (Amatriain Basilico, 2012), kümeleme algoritmaları gibi denetimsiz yöntemlerden denetimli sınıflandırıcılara kadar her tür makine öğrenimi yaklaşımını ${ }^{3}$ Netflix'te kullandıklarını söyleyerek en uygun kişiselleştirilmiş deneyimi yaratmak için abone bilgileri dâhil birçok veriden yararlandıklarını belirtirler. Bu bağlamda mühendisler, Netflix'in kullandığı veri kaynaklarını şu şekilde sıralarlar:

- İçeriğin popülerliği.

- Gün, günün saati ve cihaz türü gibi bağlamları içeren akış oynatımı.

- Üyelerin izleme kuyruklarına öge eklemesi.

- İçeriklerdeki oyuncu, yönetmen, tür, ebeveyn derecelendirmesi ve yorumlar gibi zengin meta verileri.

- Görsel sunuların üyenin eylemlerine ve etkileşimine yönelik verileri: Kaydırmalar, bilgisayar fare imleciyle üzerinde gezinmeler, tkklamalar veya belirli bir sayfada geçirilen süre.

- Sosyal veriler: Bağlantılı arkadaşlarının izlediklerini içerikler veya derecelendirmeleri.

- Netflix'teki arama terimleri.

Amatriain ve Basilico (2012), yukarıda bahsedilen iç kaynaklardan gelen verilerin haricinde öneri motorları için ayrıca, içeriğin gişe performansı, eleştirmen incelemeleri ve benzeri dış verilerden; demografi, konum, dil veya zamansal veriler gibi birçok farklı başka verilerden de yararlandıklarını ifade ederler (Amatriain ve Basilico, 2012).

\section{Sonuç ve Tartışma}

Dijitalleşmeyle birlikte bireysel uygulama olanakları oldukça gelişen sinema sa-

\footnotetext{
${ }^{3}$ Kişiselleştirme için makine öğreniminde bilinmesi gereken yöntemlerden bazıları şunlardır: Doğrusal Regresyon (Linear Regression), Lojistik Regresyon (Logistic Regression), Elastik Ağlar (Elastic Nets), Tekil Değer Ayrışması (Singular Value Decomposition), Kısıtlanmış Boltzmann Makineleri (Restricted Boltzmann Machines), Markov Zincirleri (Markov Chains), Gizli Dirichlet Tahsisi (Latent Dirichlet Allocation) ilişkilendirme Kuralları (Association Rules) Gradyan Artırımış Karar Ağaçları (Gradient Boosted Decision Trees) Rastgele Ormanlar (Random Forests) Matris Çarpanlara Ayırma (Matrix Factorization) Tüketici Veri Bilimi (Consumer Data Science).
} 
natının aynı zamanda izleme pratiklerinde de bireysel seyre doğru bir yönelim olduğu dikkati çekmektedir. Bu dönüşümün öncüsü son yıllarda kullanım yaygınlığı artan film ve dizilerin izlendiği internet tabanlı video akış siteleridir. Bu akış hizmetlerinin sinema salonlarına göre ekonomik olması, zamandan tasarruf sağlaması, bir konfor alanı olarak evde deneyimlenmesi ve aynı zamanda zengin içerikler barındırması bu öncülüğün başlıca nedenleri olarak gösterilebilir. Son yıllarda bu duruma güçlü bir katkı sunan gelişme ise akış hizmeti sağlayıcılarının yapay zekâ ve yazılım algoritmalarıyla geliştirdikleri öneri motorları aracılığıyla kişiye özel hiper kişiselleştirilmiş içerikler sunmasıdır. Bu anlamda video akış platformları abonelerini içerikler arasında yönlendirebilme yeteneğine kavuşmuştur.

Geleneksel olarak film üreticileri belli bir hedef kitle üzerine filmler üretmekte ve pazarlama stratejilerini kullanmaktadır. Film üreticileri hedef kitleyi de tahminler veya belli araştırmalar çerçevesinde belirlemekte ve risk analizlerini planlamaktadır. Bu bağlamda milyon dolarların döndüğü film endüstrisinde filmlerin doğru risk analizi hayati derecede önemlidir (Zengin, 2020, s. 159). Çevrim içi video akış siteleri ise yüksek teknolojiler kullanarak elde ettiği kullanıcıya ait çeşitli veriler sayesinde, çok daha özel ve kişisel bir iletişim ağı kurduğu kullanıcılarını bire bir temas noktalarından yakalayabilmektedir.

Netflix, yapay zekâ tabanlı kişiselleştirme algoritmalarıyla bir içeriğin türüne, oyuncularına, tarihine, izlenme geçmişine ve süresine, izlemenin gerçekleştirildiği cihazlara ve benzeri diğer verilere dayanarak abonelerine son derece yüksek düzeyde hiper kişiselleştirilmiş öneri sistemi geliştirmiştir. Netflix'in bu kişiselleştirilmiş öneri sistemi de Alvino ve Basilico'nun (2015) belirttiği gibi abonelerinin her birine doğru içeriği sunma firsatı yaratmıştır.

Medya ve eğlence endüstrisinin çok uluslu aktörlerinin de dâhil olmaya başladığı video akış pazarının pazar büyüklüğü göz önüne alındığında, ilerleyen zamanlarda her bir aboneye daha özel de iletişim kurulmaya çalışılacağı açıktır. Bu durum içerik üreticileri ve aboneler arasında ilişkiyi yakınlaştıracağı gibi aynı zamanda ticari getirisi belli olmayan hikâyelere yatırım yapan film üreticilerinin kararlarını da etkileyecektir. Bu gelişmeler çerçevesinde sinemanın üretim, dağıtım ve gösterim ayağı yeni iş akışı modelleriyle tanışacaktır. Bunun tipik bir örneği izleyicinin beyin aktivitesine göre hikâyesi değişen filmlerin üretilmesidir. Nottingham Üniversitesinden Richard Ramchurn tarafindan geliştirilen (BBC, 2018) The Moment (2018) filminin olay örgüsü izleyicinin beyin aktivitesine göre değişmektedir. Filmin seyir deneyimi ise izleyicinin beyin aktivitelerini takip eden kulaklık benzeri bir cihazla gerçekleşir. Bu cihaz beyindeki nöronların çalışmasıyla ortaya çıkan elektrik sinyallerini alır ve filmdeki olay örgüsünü geliştirir. Dolayısıyla aynen inte- 
raktif sinemada olduğu gibi bireysel düzeyde yeni bir sinemasal deneyim ortaya çıkmıştır. Bu deneyim üretim, dağıtım ve gösterim akışı bakımından yeni bir iş modelini bize sunar. Ayrıca bu tür gelişmeler toplu izleme kültüründen bireysel film izleme kültürüne doğru var olan yönelişi daha da artıracaktır.

Hiper kişiselleştirme yoluyla abonelere film ve dizi içerikleri önerilmesi beraberinde yeni tartışmaları da getirmektedir. Bu tartş̧malardan ilki, abonelerin içerik tercihlerindeki bilinç düzeyidir. Buradaki sorular şunlardır: "Platformlardaki içerikleri gerçekten abonenin kendisi mi seçmektedir?” ve “aboneler kişiselleştirilmiş tavsiyeleri neden benimsemektedir?" ikinci olarak kişisel verilerden oluşturulan önerilerin benzer içerikler sunmasıdır. Buradaki önemli sorular şunlardır: "Eğlence deneyimi kalıplaşmakta mıdır ve tek düze bir film kültürü mü oluşmaktadır?” ve "Kişiselleştirilmiş benzer içeriklerle muhatap olan izleyici, bağımsız ve özgün filmlere zamanla nasıl bir tepki verecektir?" Bütün bu soruların haricinde daha üst perdede kaygı verici bir tartşma da söz konusudur. Bu kaygı verici durum abonelerin bilgilerinden ve dijital ayak izlerinden elde edilen bilgilerin sadece öneri motorları için mi kullanılacağıdır. Bu bağlamda "Yapay zekâ algoritmalarıyla elde edilen kişisel veriler, güvenli bir şekilde nasıl saklanacak ve korunacaktır?" sorusu güncel bir tartş̧ma konusudur.

Sonuç olarak; film endüstrisi ve sinema sanat yapay zekâ çağında hem teknik hem de kültürel olarak yeni bir değişim yaşayacaktır. Üretim, dağıtım ve gösterim pratiklerinde örnekleri şimdiden görülmeye başlanan bu değişimin en önemli etkisinin seyir kültüründe olacağı ve film izleme biçiminin daha çok bireysel deneyimlere dönüşeceği bu çalışma bağlamında öngörülmektedir.

\section{Çıkar Çatışması Beyanı}

Makale yazarı herhangi bir çıkar çatışması olmadığını beyan etmiştir.

\section{Kaynakça}

Abbott, Jeffrey ve Minasian, Phill (2020). "The Modern Retailer Imperative" https://www. tcs.com/content/dam/tcs/pdf/dss/insights/the-modern-retailer-imperative.pdf Erişim tarihi: 21.09 .2020 .

Abisel, N. (2003). Sessiz Sinema. Ankara: De Ki.

Accenture (2016). "Consumers Welcome Personalized Offerings but Businesses Are Struggling to Deliver, Finds Accenture Interactive Personalization Research." https://newsroom.accenture.com/news/consumers-welcome-personalized-offerings-but-businesses-are-struggling-to-deliver-finds-accenture-interactive-personalization-research.htm Erişim tarihi: 15.09.2020. 
Accenture (2016). "Orchestrate, Organize, and Operationalize: Delivering on the Promise of Personalization @ Scale." https://www.accenture.com/_acnmedia/ PDF-34/Accenture-Personalization-Scale-POV.pdf\#zoom=50 Erişim tarihi: 19.10.2020.

Accenture (2018). "Personalization Pulse Check: Making It Personal." https://www.accenture.com/t20161011T222718__w__/us-en/_acnmedia/PDF-34/Accenture-Pulse-Check-Dive-Key-Findings-Personalized-Experiences.pdf Erişim tarihi: 19.09.2020.

Alvino, Chris ve Basilico, Justin (2015). "Learning a Personalized Homepage." https://netflixtechblog.com/learning-a-personalized-homepage-aa8ec670359a Erişim tarihi: 27.12.2020.

Amatriain, Xavier ve Basilico, Justin (2012). "Netflix Recommendations: Beyond the 5 stars (Part2)." https://netflixtechblog.com/netflix-recommendations-beyond-the-5-stars-part-2-d9b96aa399f5 Erişim tarihi: 15.12.2020.

Annas, Chloe (2020). "What Is Hyper-Personalization?" https://www.abtasty.com/blog/ what-is-hyper-personalization/ Erişim tarihi: 19.12.2020.

Arora, Shabana (2016). "Recommendation Engines: How Amazon and Netflix Are Winning the Personalization Battle." https://www.martechadvisor.com/articles/ customer-experience-2/recommendation-engines-how-amazon-and-netflix-are-winning-the-personalization-battle/ Erişim tarihi: 14.02.2020.

Ascend2 (2018). "Hyper-personalization Strategies Survey Summary Report." http://ascend2.com/wp-content/uploads/2018/12/Ascend2-Hyper-Personalization-Strategies-Report-181204.pdf Erişim tarihi: 27.11.2020.

Belton, John (2002). "Digital Cinema A False Revolution" Massachusettes Institute of Technology, (100):98-114

BBC (2018). "The Moment: How your reaction changes this film's plot." https://www.bbc. com/news/av/technology-44225476 Erişim tarihi: 07.06.2020.

BBC (2020). "Netflix gets 16 million new sign-ups thanks to lockdown." https://www.bbc. com/news/business-52376022 Erişim tarihi: 08.06.2020.

Business Week (1998). "Steve Jobs: 'There's Sanity Returning'". https://www.bloomberg. com/news/articles/1998-05-25/steve-jobs-theres-sanity-returning Erişim tarihi: 05.02.2021.

Capgemini \& Essec (2017). "Hyper-personalization vs. Segmentation: Has Big Data made customer segmentation redundant?" https://www.capgemini.com/consulting-fr/wp-content/uploads/sites/31/2017/08/hyperpersonnalisation_ vs_segmentation_english_05-01-2017.pdf Erişim tarihi: 19.09.2020.

Chandrashekar, A., Amat, F., Basilico, J., \& Cebara, T. (2017). "Artwork Personalization at Netflix." https://netflixtechblog.com/artwork-personalization-c589f074ad76 Erişim tarihi: 20.12.2020.

Dabrowski, Kevin (2020). "Hyper-Personalisation in Retail in 2021." https://www.pgs-soft. com/blog/hyper-personalisation-in-retail-2021/ Erişim tarihi: 11.12.2020.

Entefy (2018). "Al-powered hyper-personalization is the future of entertainment." https://www.entefy.com/blog/post/580/ai-powered-hyper-personalization-is-the-future-of-entertainment Erişim tarihi: 16.10.2020. 
Epsilon (2018). "New Epsilon research indicates $80 \%$ of consumers are more likely to make a purchase when brands offer personalized experiences." https:// us.epsilon.com/pressroom/new-epsilon-research-indicates-80-of-consumers-are-more-likely-to-make-a-purchase-when-brands-offer-personalized-experiences Erişim tarihi: 08.02.2021.

Epsilon (2018). "The power of me: The impact of personalization on marketing performance." https://www.slideshare.net/EpsilonMktg/the-power-of-me-the-impact-of-personalization-on-marketing-performance/1 Erişim tarihi: 08.02.2021.

Franz, Annette (2020). "How to Hyper-Personalize the Customer Experience." https:// www.getfeedback.com/resources/cx/how-to-hyper-personalize-the-customer-experience/ Erişim tarihi: 08.02.2021.

Ho, Shuk Ying (2007). "The Attraction of Internet Personalization to Web Users." Electronic Markets 16(1): 41-50.

IBM, \& Econsultancy (2015). "4 Out Of 5 Consumers Declare Brands Don't Know Them As An Individual, According to IBM and Econsultancy Study." https://www-03. ibm.com/press/us/en/pressrelease/46454.wss Erişim tarihi: 26.12.2020.

Jain, Geetika, Justin Paul ve Archana Shrivastava (2021). "Hyper-personalization, Co-creation, Digital Clienteling and Transformation." Journal of Business Research Volume 124: 12-23.

Jain, Geetika, v.d., (2018). "Hyper-Personalization - Fashion Sustainability Through Digital Clienteling." Research Journal of Textile and Apparel: 320-334.

Jha, Manu Siddharth (2019). "Is Artificial Intelligence the next big thing in Hollywood?" https://www.mygreatlearning.com/blog/is-artificial-intelligence-the-next-big-thing-in-hollywood/ Erişim tarihi: 26.04.2020.

Jarvie, I.C. (1993). "Sosyal Bir Kurum Olarak Sinemaya Gitmek", Çev. Gülseren Güçhan, 25. Kare, (5):22-25

Chellappa, Ramnath K. ve Sin, Raymond (2005). "Personalization versus Privacy: An Empirical Examination of the Online Consumer's Dilemma." Information Technology and Management 6(2): 181-202.

Kaiser, Andy (2020). "When and how should I personalize my customer experience?" https://medium.com/ninetailed/when-and-how-should-i-personalize-my-customer-experience-68610d03a219 Erişim tarihi: 04.09.2020.

Kapır, Bahadır (2019). "Küreselleşme Sürecinde Dijital Medya Platformlarının Ekonomisi ve İçerik Üretim Süreci:Netflix ve Blutv Örneği." Endüstri 4.0 ve Dijital Medya. Filiz Aydoğan (der.) içinde. İstanbul: Der. 219-242.

Kırel, S. (2010). Kültürel Çalışmalar ve Sinema. İstanbul: Kırmızı Kedi.

Kumar, Ashok (2008). "From mass customization to mass personalization: a strategic transformation." International Journal of Flexible Manufacturing Systems, s. 533-547.

Lebo, Todd (2019). "Hyper-Personalization: What It Is and Why You Need It in Your 2019 Marketing." https://www.convinceandconvert.com/research/hyper-personalization/\#: :text=What\%20is\%20hyper\%2Dpersonalization\%3F,personalized\%20marketing\%20a\%20step\%20further Erişim tarihi: 17.09.2020. 
Lui, Herbert (2021). "What the Netflix TechBlog Says to 250,000 Pageviews Every Month." https://entrepreneurshandbook.co/what-the-netflix-techblog-says-to250-000-pageviews-every-month-e9af3ab76b5a Erişim tarihi: 15.15.2021.

Maayan, Gilad (2020). "Hyper Personalization: Customizing Service With Al." https:// www.computer.org/publications/tech-news/trends/hyper-personalization-customizing-service-with-ai Erişim tarihi: 18.09.2020.

Mandeep, Vijay (2019). "How Hyper-Personalized Marketing Can Deliver Better Customer Experiences at Scale." https://medium.com/hackernoon/how-hyper-personalised-marketing-can-deliver-better-customer-experiences-at-scale-af94405a6fdf Erişim tarihi: 13.01.2021.

Manovich, Lev (1995). "What is the Digital Cinema?" http://manovich.net/index.php/ projects/what-is-digital-cinema Erişim tarihi: 27.12.2020.

Manovich, Lev (2014). "HTML'den Borges'e Yeni Medya". Yeni Medyaya Eleştirel Yaklaşımlar. Mukadder Çakır (der.) içinde. İstanbul: Doğu Kitabevi. 157-182.

McAlone, Nathan (2016). "Why Netflix thinks its personalized recommendation engine is worth $\$ 1$ billion per year." https://www.businessinsider.com/netflix-recommendation-engine-worth-1-billion-per-year-2016-6? r=US\&IR=T Erişim tarihi: 27.08.2020.

Medium (2019). "Hyper-Personalization: The Next Wave of Customer Engagement." https://medium.com/smartkarrot/hyper-personalization-the-next-wave-of-customer-engagement-9e68c7a7c9ad Erişim tarihi: 15.09.2020.

Mialki, Stephanie (2019). "Hyper-Personalized Marketing: How to Do It Right with 3 Examples to Prove It." https://instapage.com/blog/hyper-personalization Erişim tarihi: 25.09.2020.

Monaco, J. (2002). Bir Film Nasıl Okunur? İstanbul: Oğlak.

Montgomery, Alan L. ve Smith, Micheal D. (2009). "Prospects for Personalization on the Internet." Journal of Interactive Marketing 23(2): 130-137.

Nelson, Nick (2016). "The Power of a Picture." https://about.netflix.com/en/news/thepower-of-a-picture Erişim tarihi: 02.01.2021.

Netflix (2016). "Meson: Workflow Orchestration for Netflix Recommendations." https:// netflixtechblog.com/meson-workflow-orchestration-for-netflix-recommendations-fc932625c1d9 Erişim tarihi: 28.12.2020.

Netflix (2016). "Selecting the best artwork for videos through A/B testing." https://netflixtechblog.com/selecting-the-best-artwork-for-videos-through-a-b-testingf6155c4595f6 Erişim tarihi: 03.12.2020.

Netflix (2018). "The Netflix Media Database." https://netflixtechblog.com/the-netflix-media-database-nmdb-9bf8e6d0944d Erişim tarihi: 28.12.2020.

Özuyar, A. (2017). Sessiz Dönem Türk Sinema Tarihi (1895-1922). İstanbul: Yapı Kredi Yayınları.

Priyam, Jha (2019). "Why Hyper-Personalization Is The Future Of Marketing (And How To Do It)." https://webengage.com/blog/hyper-personalization-marketing-future/ Erişim tarihi: 16.10.2020.

Rosenbaum, Mark S, v.d., (2019). "The Product Is Me: Hyper-Personalized Consumer Goods As Unconventional Luxury". Journal of Business Research. 
Segal, Eddie (2020). "Al-based Hyper Personalisation for Enhanced Customer Experience." https://developer.ibm.com/recipes/tutorials/aibased-hyper-personalisation-for-enhanced-customer-experience/ Erişim tarihi: 08.02.2021.

Smith, Wendell R. (1956). "Product Differentiation and Market Segmentation as Alternative Marketing Strategies." Journal of Marketing 21(1): 3-8.

Statista (2020). "Leading companies worldwide in 2020, by brand value." https://www. statista.com/statistics/269444/brand-value-of-the-most-valuable-companies-worldwide/ Erişim tarihi: 10.01.2021.

Statista. (2021). "Number of Netflix paid subscribers worldwide from 1st quarter 2013 to 1st quarter 2021." https://www.statista.com/statistics/250934/quarterly-number-of-netflix-streaming-subscribers-worldwide/\#: :text=Netflix\%20had\%20207.64\%20million\%20paid,Netflix's\%20total\%20global\%20 subscriber\%20base. Erişim tarihi: 19.06.2021.

Subramanyan, Vignesh (2014). "What's The Hype Around 'Hyper-Personalization'?" https://www.business2community.com/marketing/whats-hype-around-hyper-personalization-01045882\#1vy Erişim tarihi: 19.09.2020.

Sunikka, Anne ve Bragge, Johanna (2009). "Personalization and Mass-Customization in the Research Literature." 5th World Conference on Mass Customization and Personalization (MCPC) 4-8 Ekim 2009. Helsinki.

Three Deep (2018). "Hyper-Personalization: Happier Customers, Happier Marketers." https://www.threedeepmarketing.com/blog/hyper-personalization-happier-customers-happier-marketers Erişim tarihi: 08.02.2021.

Trafton, Anne (2014). "In the Blink of an Eye." https://news.mit.edu/2014/in-the-blink-ofan-eye-0116 Erişim tarihi: 04.01.2021.

Tyagi, Neelam (2019). "6 Dynamic Challenges in Formulating the Recommendation System." https://www.analyticssteps.com/blogs/6-dynamic-challenges-formulating-imperative-recommendation-system Erişim tarihi: 26.12.2020.

Wind, Jeery ve Rangaswamy, Arvind (2001). "Customerization: The Next Revolution in Mass Customization." Journal of Interactive Marketing 15(1): 13-32.

Zengin, Ferhat (2020). "Akıllı Makine Çağı Sinemasına Giriş: Sinema Sanatında Yapay Zekâ Teknolojilerinin Kullanımı." İletişim Çalışmaları Dergisi 6(2): 151-177. 